\title{
Relacionamentos entre empresas na cadeia de suprimentos de uma montadora de motores - uma discussão a partir dos elementos da Teoria de Custos de Transação
}

\author{
Jonas Lucio Maia ${ }^{1}$ \\ Aline Lamon Cerra ${ }^{2}$
}

\begin{abstract}
Resumo: Este trabalho tem por objetivo compreender os relacionamentos "montadora-fornecedor" verificados dentro de uma cadeia de suprimentos do setor automobilístico brasileiro, com base nos pressupostos e variáveis da Economia de Custos de Transação. A Economia de Custos de Transação tem se mostrado uma teoria importante para pesquisa em cadeias, podendo ser utilizada para avaliar a qualidade e a riqueza das relações entre empresas; considerar as implicações das escolhas organizacionais em desenvolver uma atividade internamente à empresa, no mercado ou através de formas híbridas, entre outras. Os principais resultados indicam que (1) as montadoras utilizam relação híbrida com seus fornecedores, que em momentos se aproxima da concorrência "latente" e em momentos se aproxima da cooperação, (2) a questão da desverticalização afeta diretamente a assimetria informacional existente entre as partes e (3) a relação entre especificidade de ativos e comportamento oportunista é mediada por questões como volumes da transação e maximização de investimentos anteriores.
\end{abstract}

Palavras-chave: cadeias de suprimentos; Economia de Custos de Transação; Indústria automobilística.

\footnotetext{
1 Doutorando em Engenharia de Produção, Universidade Federal de São Carlos (UFSCar) - Grupo de Estudos sobre Estratégia e Organização da Produção. E-mail: jonasmaia@dep.ufscar.br. Os autores gostariam de agradecer ao CNPq (Conselho Nacional de Desenvolvimento Científico e Tecnológico) pelo apoio financeiro ao projeto "Estratégias de produção das unidades produtoras de motores para automóveis - Processo 477515/o3-7", que teve papel importante na viabilidade desta pesquisa.

2 Doutora em Engenharia de Produção, Universidade Federal de São Carlos (UFSCar) - Grupo de Estudos sobre Estratégia e Organização da Produção. E-mail: alinelc@terra.com.br. A autora gostaria de agradecer à FAPESP (Fundação de Amparo à Pesquisa do Estado de São Paulo) pela concessão da bolsa de Pós-Doutorado - "Estratégias tecnológicas em três cadeias de suprimentos do segmento de motores para automóveis (Processo 05/59798-5)", também inserida no contexto desta pesquisa.
} 


\title{
Supply chain relations towards a car engine company: a study from a transaction cost perspective
}

\begin{abstract}
This paper aims at shedding light to the "automaker-supplier" relationships taking place inside a supply chain belonging to the Brazilian automotive industry, based on the Transaction Cost Economics assumptions and variables. Transaction Cost Economics has proven to be an important theoretical basis for studies on chains, being used to assess the quality and richness of the relationships; to consider the impacts of organizational choices in performing an activity inside the company, in the market or through hybrid forms; among others. The main results show that (1) the engine manufacturers use a hybrid form of relationship with their suppliers, which alternates from cooperation to "latent competition", (2) deverticalization directly affects both transaction parties, and (3) the relation between asset specificity and opportunistic behavior is mediated by issues like transaction volume and maximization of return on previous investments.
\end{abstract}

Key words: supply chains; Transaction Cost Economics; automotive industry.

JEL: L14

\section{Introdução}

São relativamente recentes os esforços para o desenvolvimento de abordagens para o estudo de cadeias de suprimentos. Apenas no final da década de 80 o assunto começou a ser sistematicamente tratado em periódicos científicos no ocidente, de forma concomitante à difusão do novo padrão de relacionamento "montadora-fornecedor" oriundo da indústria automobilística japonesa (Alves Filho et al. 2004).

No contexto deste novo padrão de relacionamento observado na indústria automobilística japonesa, destacam-se as relações de parcerias entre as firmas da cadeia de suprimentos (Womack et al. 1992 \& Dyer \& Ouchi 1993 \& Liker \& Wu 2000). Nas relações de parceria, as empresas envolvidas buscam partilhar maior volume de informações e coordenar melhor tarefas interdependentes (Clark \& Fugimoto 1991 \& Nishigushi 1994), de forma a baixarem custos, melhorarem a qualidade e aumentarem a velocidade de desenvolvimento de produtos (Dyer 1996).

Além do desenvolvimento de relações de parceria, outra tendência verificada nas cadeias automotivas é a concentração da base de fornecimento em um número menor de empresas. Segundo Alves Filho et al. (2001), as montadoras têm agido no sentido de contar com um pequeno número de fornecedores diretos de componentes, os chamados fornecedores de primeiro nível, que, por sua vez, subcontratam uma série de outras empresas menores, os fornecedores secundários e terciários, alguns muito pequenos. Segundo Mcmillan (1990), quanto mais baixa a posição do fornecedor na hierarquia, a tendência é que menos sofisticados tecnologicamente sejam os produtos por ele fornecidos. 
A partir da difusão dessas práticas japonesas, cresceram exponencialmente tanto a literatura de cunho mais prescritivo quanto aquela que analisa as situações e as práticas implementadas para a coordenação ou gestão de cadeias de suprimentos.

No contexto dessas alterações nas práticas das empresas e dos desenvolvimentos teóricos correspondentes, diversas abordagens têm sido utilizadas no sentido de analisar as cadeias de suprimentos e as relações entre empresas. Cada uma dessas abordagens tem suas origens em áreas distintas do conhecimento, como a Economia, a Sociologia, a Administração de Empresas, entre outras, possuindo pressupostos, aplicações e focos de análise diferentes.

Uma dessas abordagens é a Economia de Custos de Transação (ECT), que adota uma perspectiva institucional para a análise das cadeias. Em linhas gerais, tal perspectiva auxilia no entendimento das diferentes formas de coordenação a que as organizações estão sujeitas e das diferentes formas de conexões entre empresas (ou unidades produtivas) em uma determinada cadeia. (Trienekens 1999)

A ECT, foco desse estudo, assume que a transação deve ser a unidade básica de análise e, assim, busca estudar como parceiros em uma transação protegemse dos riscos associados às relações de trocas e buscam minimizar os custos incorridos quando bens e serviços cruzam fronteiras organizacionais. (Klein \& Shelanski 1994:2 apud Farina \& Azevedo \& Saes 1999)

De forma central à abordagem proposta pela ECT está o conceito de custo de transação, que é incorrido toda vez que um bem ou serviço é transferido pelo que Williamson (1981:552) denomina “interface tecnologicamente separável”. Dessa forma, assume-se que além dos importantes custos de produção internos a firmas, existem custos de transação, também relevantes, inerentes à relação entre as firmas.

Alternando do pólo teórico para o empírico deste trabalho - a indústria automobilística brasileira - temos que, conforme destacam Maia et al. (2005) e Alves Filho et al. (2006), o padrão do relacionamento entre empresas nessa indústria apresenta diferenças e especificidades inerentes a cada relação, no que tange à estrutura das cadeias de suprimentos, à proximidade das relações e às atividades desenvolvidas no contexto das mesmas, entre outros aspectos.

Assim, a questão de pesquisa que se coloca neste trabalho é: considerando a diversidade verificada previamente nas cadeias do setor automotivo brasileiro, como a Economia de Custos de Transação pode prestar contribuição no sentido de analisar e explicar, mesmo que parcialmente, os aspectos configuracionais das cadeias, bem como as atividades desenvolvidas e decisões tomadas dentro das mesmas?

Nesse contexto, este trabalho tem por objetivo compreender os relacionamentos "montadora-fornecedor" verificados dentro de uma cadeia de suprimentos do setor automobilístico brasileiro, com base nos pressupostos e nas variáveis da Economia de Custos de Transação. Para esse propósito, o presente trabalho 
utilizará estudos de caso realizados em uma montadora de motores para automóveis e três dos seus fornecedores.

Esse objetivo principal pode ser desdobrado ao menos em três objetivos secundários: (1) retratar os diversos aspectos relacionados à relação entre as empresas, como: clientes atendidos, fornecedores utilizados, produtos transacionados, autonomia e conteúdo tecnológico, etc.; (2) explorar as questões "ambientais" da ECT - especificidade de ativos, complexidade e incerteza e freqüência - nesses relacionamentos; e (3) abordar os aspectos "comportamentais" da ECT - racionalidade imitada e oportunismo - nessas relações.

A próxima seção realiza uma explanação acerca de conceitos relativos à Economia de Custos de Transação. A seguir, apresenta-se a literatura a respeito das relações entre firmas no setor automobilístico, envolvendo resultados de pesquisas empíricas já realizadas e, na seqüência, discute-se o método utilizado e os estudos de caso em si. Na última seção, têm-se as considerações finais do trabalho.

\section{A economia dos custos de transação}

Até a década de 30, a teoria econômica existente reconhecia a existência de tipos variados de custos, mas acreditava que os custos econômicos associados a transações de compra e venda eram negligenciáveis frente aos custos de produção. De tal fato decorre a grande importância dada a estes últimos, em detrimento dos outros dois primeiros, nos avanços do ferramental de análises econômicas presentes até então (Fiani 2002).

Somente com a publicação pioneira por Ronald Coase em 1937, de seu artigo intitulado "The Nature of The Firm", essa visão preponderante começou a ser alterada. Segundo Azevedo (1996), a preocupação apresentada por Coase era a de entender o escopo, a abrangência e os limites de uma empresa. Desejava-se analisar o porquê da existência de diversas firmas, ao invés da opção da centralização de todas as atividades dentro de uma grande empresa, que atuasse em todas as etapas do processo produtivo.

Ainda segundo Azevedo (1996), Coase identificou que as trocas, o estabelecimento de acordos ou qualquer resultado de uma transação entre os agentes econômicos apresentavam custos, os quais poderiam ser relativos à coleta de informações ou concernentes à negociação e ao estabelecimento de um acordo entre as partes. Tais custos foram genericamente denominados de Custos de Transação, e se iniciaram os estudos sobre as condições nas quais tais custos deixam de ser desprezíveis e passam a ser elemento importante de análise nas decisões dos agentes econômicos. (Fiani 2002)

Buscando uma definição formal para Custos de Transação, podemos apresentá-los como os "custos ex-ante de esboçar, negociar e salvaguardar um acordo e, sobretudo, os custos ex-post decorrentes de problemas de adaptação que surgem quando a execução de um contrato é imprecisa como resultado de atrasos, erros ou omissões" (Azevedo 1996:221). 
Dessa forma, segundo Klein \& Shelanski (1994:2) apud Farina et al. (1999) e Mcnally (2002), a ECT estuda como parceiros em uma transação se protegem dos riscos inerentes às relações de trocas, explorando os custos econômicos associados com as estruturas de governança requeridas para completar a transação, com o intuito de minimizar os custos de transação por meio da forma organizacional escolhida.

Na linha do que foi previamente colocado, custos de transação são os custos de negociar, redigir e garantir o cumprimento de um contrato (Fiani 2002). Uma vez que são atribuídos custos aos contratos, tem-se o rompimento com uma das hipóteses da abordagem microeconômica clássica: a simetria de informações. Surge, em seu lugar, um novo conjunto de hipóteses.

Tais hipóteses são os fatores determinantes dos custos de transação: especificidade dos ativos, complexidade e incerteza, freqüência das transações, racionalidade limitada e oportunismo. Os três primeiros se referem a aspectos ambientais, ao passo que os dois últimos abrangem questões comportamentais. (Williamson 1985)

A "racionalidade limitada" advoga que os indivíduos, embora sejam intencionalmente racionais, enfrentam limitações no acúmulo, processamento e transmissão de informações. Tais limitações humanas impossibilitam que os contratos incorporem cláusulas que antecipem qualquer circunstância futura.

Assim, devido à racionalidade limitada dos tomadores de decisão, a distribuição assimétrica de informação e a inabilidade de especificar completamente o comportamento dos agentes nas presenças de múltiplas contingências, a ECT considera que todos os contratos são incompletos e portanto sujeitos a renegociações e possibilidade de comportamento oportunista. (Leiblein \& Miller 2003)

No que diz respeito ao “comportamento oportunista”, considera-se que não há restrições ao comportamento egoísta dos agentes econômicos, o que implica dizer que as partes podem se aproveitar de uma negociação, impondo perdas à(s) sua(s) contraparte(s) na transação. Uma parte pode agir aeticamente antes de se efetivar a transação (oportunismo ex-ante) ou o comportamento aético pode ser verificado durante a vigência do contrato (oportunismo ex-post).

Racionalidade limitada e ações oportunistas aumentam os custos de transação, e esses custos crescem conforme aumentam a "especificidade dos ativos" e a "incerteza” envolvidas na transação. (Grover \& Malhotra 2003)

A "especificidade dos ativos" se refere a ativos que quando utilizados para outro fim, que não aquele inicialmente acordado, sofrem perda de valor, consistindo portanto em investimentos duráveis comprometidos em uma transação específica. Quando duas partes ou mais realizam investimentos específicos, pode surgir uma situação de dependência mútua, na qual provavelmente haverá incentivos para que o contrato não seja rompido e continue indefinidamente ou por um tempo predeterminado. 
Conforme a especificidade dos ativos aumenta, mais complexas estruturas de governança (ou seja, contratos mais complexos) são requeridas para atenuar barganhas sobre lucros de ativos específicos (Williamson 1985). Quanto maior a especificidade, maiores serão os riscos e problemas de adaptação e, portanto, maiores os custos de transação.

Williamson (1979) apud Mcnally (2002) identificou três tipos de especificidade dos ativos:

- especificidade locacional (site specificity) - refere-se à situação pela qual sucessivos estágios de produção que são imóveis por natureza são localizados próximos a outros para melhorar coordenação e economizar em custos de inventários e transportes;

- especificidade de ativos físicos (physical asset specificity) - refere-se a investimentos específicos de capital (isto e, em maquinaria customizada, ferramentas, etc.); permite por exemplo a diferenciação de produtos e pode melhorar a qualidade aumentando a integridade do produto;

- especificidade de ativos humanos (human asset specificity) - refere-se a específico know-how acumulado pelas pessoas envolvidas nas transações em relações de longo prazo.

Mais três tipos de especificidade de ativos são considerados por Williamson (1991:281):

- ativos dedicados - refere-se a investimento do qual o retorno está relacionado a uma transação particular, sendo relevante individualmente;

- especificidade de marca - tem como exemplo as franquias, nas quais transações baseadas na concessão de uso de uma determinada marca por terceiros são realizadas.

- $\quad$ especificidade temporal - o valor de uma transação depende do tempo em que ela se processa.

A "incerteza" característica de uma transação pode ser determinante na escolha de uma estrutura de governança. O papel que a incerteza representa é o de revelar os limites da racionalidade limitada e, portanto, evidenciar a incompletude dos contratos (Farina et al. 1999). Vale ressaltar que diferentes tipos de incerteza afetam a duração dos contratos (Azevedo \& Rocha 2003).

A "freqüência das relações" também possui impacto nos custos de transação. Em decorrência da repetição da relação, as partes podem adquirir conhecimento umas das outras (reduzindo incerteza), criar reputação em torno de um marca (gerando ativo específico) e, em alguns casos, criar um compromisso confiável de continuidade de relação (Farina et al. 1999). 
ECT explora os custos econômicos associados com as estruturas de governança que são requeridas para completar a transação, predizendo que a forma organizacional que minimiza custos de transação será escolhida (Mcnally 2002). Assim, a principal questão que a ECT trabalha, segundo Williamson (1994), é o alinhamento de transações (as quais diferem em seus atributos), com estruturas de governança (as quais diferem em seus custos e competências).

Segundo Barney (1999), governança consiste em mecanismo usado pelas firmas mediante a realização de trocas econômicas com a finalidade de atenuar a ameaça de oportunismo. A finalidade da salvaguarda é fornecer, a um custo mínimo, o controle e a confiança que são necessários para as pessoas envolvidas na transação acreditarem que o envolvimento nas trocas será melhor opção do que não fazê-lo. Existem três formas de governança (Barney 1999 \& Mcnally 2002): mercado spot (transações em que ocorre instantânea transferência de produtos ou serviços), integração vertical ou hierarquia (mecanismo utilizado para gerenciar trocas econômicas dentro das próprias fronteiras da firma) e híbrida (mecanismo utilizado para gerenciar trocas econômicas através de subcontratações, alianças e franquias, entre outras, combinando aspectos de mercado e integração vertical).

Segundo Williamson (1999), a questão das competências estratégicas das firmas deve ser considerada na decisão entre "fazer ou comprar". Segundo o autor, "governança e competências são ao mesmo tempo complementares e rivais", sendo que a "governança é microanalítica (a transação é a unidade básica de análise) e adota uma abordagem econômica para avaliar o comportamento das organizações, enquanto que competências são mais complexas (rotina é a unidade de análise) e são mais relacionadas com processos (especialmente aprendizagem) e elementos da estratégia” (Williamson 1999:1106).

\section{A ECT e as relações entre firmas na indústria automobilística: evidências empíricas}

Esta seção visa ilustrar, partindo de evidências empíricas, aplicações práticas dos elementos da ECT introduzidos na seção anterior. Para tal, procurou-se identificar na literatura estudos que apresentassem casos sobre cadeias de suprimentos no setor automotivo.

Dyer (1997), ao estudar relações interfirmas na indústria automobilística, não observou que os custos de transação necessariamente aumentam com o aumento da especificidade dos ativos. Para Williamson (1985), custos de transação tendem a aumentar conforme aumenta a especificidade dos ativos devido à presença de oportunismo envolvido nas transações. Dyer (1997) realizou um estudo exploratório envolvendo transações de 50 fornecedores com montadoras, nos Estados Unidos e no Japão. O grupo japonês (Toyota e Nissan) apresentou-se com maior especificidade de ativos e com menores custos de transação, quando comparado ao grupo americano (Chrysler, GM e Ford). Atribuiu-se isso aos seguintes fatos: 
- japoneses realizam repetidas transações com pequeno número de fornecedores, quando comparados aos americanos;

- altos volumes de trocas entre as partes envolvidas nas transações;

- extensa informação interfirmas e reduzida assimetria de informação;

- boa reputação e confiança: salvaguardas não contratuais;

- investimentos em ativos coespecializados, envolvendo relações de longo prazo com maior interdependência entre partes envolvidas nas transações.

Isso significa que diferentes salvaguardas podem ser empregadas para controlar o oportunismo e que elas apresentam diferentes custos, o que resulta em custos de transação diferenciados em diferentes horizontes de tempo.

Os estudos de Folta (1998) apontam para resultados similares. Segundo os autores, quanto maior o grau de especificidade dos ativos, mais próximas tendem a ser as relações entre a firma e seus fornecedores. Segundo Combs \& Ketchen Jr (1999), sob certas condições a especificidade dos ativos encoraja a cooperação interfirmas: quando ambas firmas em um acordo cooperativo investem em ativos específicos, os ativos formam uma dependência recíproca, o que incentiva cada parceiro a evitar ações oportunísticas.

Para Dyer (1996), transações que envolvem investimentos específicos são mais prováveis de resultarem em vantagens competitivas quando as partes envolvidas têm desenvolvido salvaguardas nas quais podem controlar o oportunismo a um custo relativamente baixo e as tarefas/atividades são caracterizadas por um alto grau de interdependência.

Aduração do relacionamento também éfator importante, dado que, para Lorenzoni \& Lipparini (1999), repetidas transações entre firmas, com o decorrer do tempo, levam a custos de transação mais baixos, o que permite que os atores econômicos ganhem vantagem subcontratando fornecedores que desenvolvem suas próprias competências. Para Swaminathan et al. (2002), os benefícios da relação de longo prazo surgem de três fontes relacionadas: o desenvolvimento de conhecimento de cada parceiro, o desenvolvimento de confiança e o desenvolvimento de relações de rotinas específicas.

Kotabe et al. (2003) examinaram relacionamentos entre compradores e fornecedores do setor automobilístico no Japão e nos Estados Unidos, analisando duas formas de trocas de conhecimentos envolvidas nessas relações: (1) troca de conhecimentos técnicos e (2) trocas nas quais ocorre transferência de tecnologia; nesse contexto, eles consideraram a duração do relacionamento (se é de longo prazo ou não), com atenção especial para melhoria de desempenho de fornecedores. Os resultados do survey realizado indicaram que a duração da relação não é significativa para efeitos de trocas de conhecimentos técnicos, oposto ao que ocorre em trocas tecnológicas, nas quais os efeitos positivos aumentam conforme a duração também aumenta. A análise empírica confirma que transferência de conhecimento pode ser associada com melhoria de desempenho de fornecedores em ambos os países estudados. 
Confiança, em relações comprador-fornecedor, pode ser importante fonte de vantagem competitiva porque (Dyer \& Chu 2000): (1) proporciona menores custos de transação (Dyer 1996 \& Zaheer et al. 1992); (2) facilita investimentos em relações que envolvem ativos específicos (Dyer 1996); e (3) leva a desempenho superior das rotinas para partilhar informações (Fruin 1992 \& Clark \& Fujimoto 1991 \& Nishigushi 1994).

Dyer \& Chu (2000) realizaram uma pesquisa que envolveu compradores e fornecedores do setor automobilístico no Japão, nos Estados Unidos e na Coréia. Os resultados obtidos indicaram que o ambiente institucional tem importante influência no desenvolvimento de confiança interorganizacional, mas práticas específicas das firmas talvez tenham uma importância mais significativa, devido ao fato da pesquisa revelar que produtores japoneses transplantados nos Estados Unidos construíram níveis mais altos de confiança com fornecedores americanos do que os próprios produtores americanos construíram. Esses autores atribuem como fatores determinantes principais a assistência que esses produtores dispensam aos fornecedores, os relacionamentos de longo prazo e o processo de seleção de fornecedores que realizam.

Em linhas gerais, os artigos aqui analisados relatam pesquisas empíricas que podem ilustrar características de cadeias de suprimentos relacionadas aos elementos da ECT previamente abordados.

\section{Método de pesquisa}

A estratégia de pesquisa adotada foi o estudo de caso, pois, em consonância com Yin (1994:23), desejava-se "investigar um fenômeno atual dentro do seu contexto de realidade, quando as fronteiras entre o fenômeno e o contexto não são claramente definidas e no qual são utilizadas várias fontes de evidência". De forma a permitir comparações cruzadas entre os dois relacionamentos analisados, fez-se opção pelo estudo de caso multicaso.

A técnica de obtenção de dados empreendida foi a de entrevista, que, segundo Selltiz et al. (1967: 273) apud Gil (1999),

É bastante adequada para a obtenção de informações acerca do que as pessoas sabem, crêem, esperam, sentem ou desejam, pretendem fazer, fazem ou fizeram, bem como acerca das suas explicações ou razões a respeito das coisas precedentes.

Dado o caráter de algumas questões estudadas neste trabalho serem específicas às empresas, optou-se pelo uso das entrevistas semi-estruturadas, de modo a conseguir maior flexibilidade para analisar tais especificidades. Embora não seja de interesse descrever pormenorizadamente o instrumento de pesquisa, é relevante registrar a utilização de um questionário formulado a partir da revisão da literatura, cujas questões estavam divididas em duas partes: a primeira abordou a estrutura das cadeias de suprimentos e a segunda tratou de aspectos referentes às relações entre empresas dentro das cadeias. Permeando ambas as partes do questionário, estavam perguntas que propiciassem investigar tanto aspectos gerais como clientes atendidos, fornecedores 
utilizados, produtos transacionados, autonomia e conteúdo tecnológico, etc. quanto elementos relacionados à ECT, principalmente em seus aspectos de especificidade de ativos e freqüência de relações.

Optou-se pela focalização nesses dois aspectos da ECT (especificidade de ativos e freqüência) por se acreditar que estes seriam os mais plausíveis de serem identificados por meio do questionamento direto aos entrevistados. Questões como oportunismo, incerteza e racionalidade limitada foram deixadas para a análise interpretativa dos pesquisadores, análise esta embasada no conjunto dos dados colhidos durante a pesquisa de campo.

Cada entrevista durou cerca de uma hora, com o número de entrevistas variando de empresa para empresa em virtude do tempo disponibilizado pela companhia para a realização do estudo.

As informações obtidas nas empresas serão descritas e comparadas por meio de tabelas na seção a seguir, que trata dos estudos de caso.

\section{Estudos de caso}

Os estudos de caso foram realizados em uma montadora de motores para automóveis do setor automobilístico brasileiro e em três de seus fornecedores. De forma a não identificá-los, eles serão aqui chamados de "montadora" e fornecedores "A", "B" e "C". O quadro a seguir sintetiza as entrevistas realizadas nas empresas estudadas:

\begin{tabular}{|c|c|c|c|c|}
\hline & MONTADORA & FORNECEDOR “A” & FORNECEDOR “B” & FORNECEDOR "C" \\
\hline Entrevistados & $\begin{array}{c}\text { Gerente Executivo } \\
\text { de Engenharia } \\
\text { Engenheiro } \\
\text { Industrial } \\
\text { Supervisor de } \\
\text { Compras } \\
\text { Responsável pela } \\
\text { Logística }\end{array}$ & $\begin{array}{c}\text { Engenheiro de } \\
\text { Desenvolvimento } \\
\text { Gerente } \\
\text { Administrativo } \\
\text { Coordenador } \\
\text { Logístico } \\
\text { Gerente de } \\
\text { Compras }\end{array}$ & $\begin{array}{c}\text { Engenheiro de } \\
\text { Desenvolvimento } \\
\text { Gerente de Vendas } \\
\text { Gerente de } \\
\text { Compras }\end{array}$ & $\begin{array}{l}\text { Responsável pela } \\
\text { Produção } \\
\text { Responsável pela } \\
\text { Logística }\end{array}$ \\
\hline
\end{tabular}

\section{QUADRO 1 - ENTREVISTAS REALIZADAS NAS EMPRESAS ESTUDADAS.}

Embora as entrevistas sejam providas de informações gerais das empresas e do contexto no qual operam, a opção pelo anonimato das companhias se justifica no sentido de permitir aos autores deste artigo a imparcialidade e a criticidade de análise necessária a um trabalho de cunho acadêmico-científico, de forma independente às empresas analisadas.

Além disso, embora a pesquisa se utilize de métodos como verificação documental dos dados, entre outros, as informações colhidas durante as entrevistas possuem caráter extremamente relevante para a investigação. Dessa forma, no entender dos autores, o anonimato permite que os entrevistados possam contribuir com maior franqueza e independência durante o processo de obtenção de informações. 
A montadora produz motores para automóveis (motores 1.0 a 1.6), com uma grande diversidade de produtos. A fábrica foi instalada recentemente com inovações na linha de produção, principalmente por meio do uso de robôs. Trabalha em 3 turnos de produção, e cada turno possui a capacidade de produzir 600 motores, mas manufatura 550 devido ao mix de produção. Dessa forma, a planta possui capacidade de produção aproximada de 40 mil motores por mês, dos quais cerca de 3 mil são exportados.

O fornecedor "A" produz embreagens, com 60 famílias de produtos na linha de veículos leves e mais 60 famílias de produtos na linha de veículos pesados. Atualmente trabalhando em 3 turnos e com 20\% de capacidade ociosa, a empresa fabrica todos os produtos relacionados às embreagens, desde o cilindro mestre no pedal até o volante de dupla massa no virabrequim.

O fornecedor "B" fabrica molas, sendo considerado tanto um fornecedor de primeiro nível da montadora, por lhe fornecer molas de válvulas de motores, quanto um fornecedor de segundo nível, na medida em que provê molas para os seus fornecedores, as empresas de autopeças, incluindo a empresa "A".

O fornecedor "C", ao contrário das demais empresas estudadas, possui 100\% de capital nacional. Produz coletores de escapamento, com 12 tipos de peças e 110 modelos, em 2 turnos diários.

A figura 1 ilustra os relacionamentos verificados entre as quatro empresas do estudo de caso.

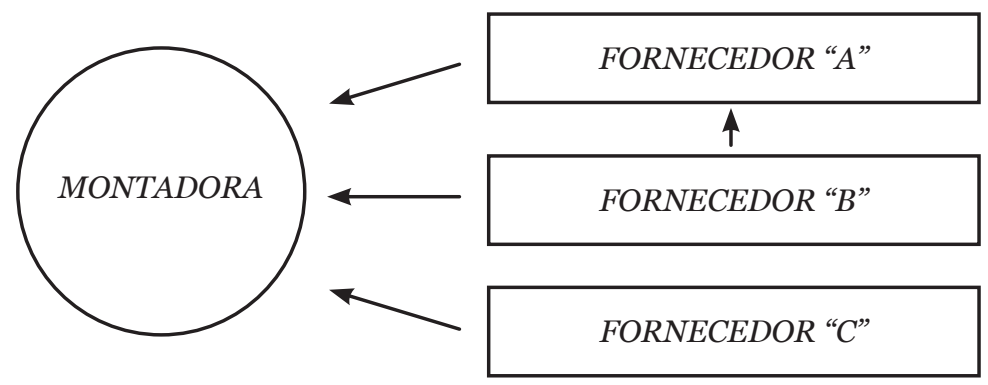

FIGURA 1 - RELACIONAMENTO ENTRE EMPRESAS DO CASO

De forma a permitir a análise cruzada entre as empresas, optou-se aqui por apresentar os dados de forma tabular e não em texto corrente. O Quadro 2 a seguir sintetiza as principais informações relativas às empresas estudadas. Nesse quadro, focalizam-se os dados gerais das companhias, aspectos da cadeia de suprimentos nas quais estão envolvidas, bem como dados dos produtos que manufaturam. 


\begin{tabular}{|c|c|c|c|c|}
\hline & MONTADORA & FORNECEDOR "A" & FORNECEDOR "B" & FORNECEDOR “C” \\
\hline $\begin{array}{l}\text { Plantas } \\
\text { localizadas } \\
\text { no Brasil }\end{array}$ & $\begin{array}{l}\text { Existem cinco } \\
\text { plantas. Neste } \\
\text { trabalho estudou-se } \\
\text { uma fábrica de uma } \\
\text { das plantas. }\end{array}$ & $\begin{array}{l}\text { Existem duas } \\
\text { plantas, uma delas } \\
\text { estudada neste } \\
\text { trabalho. }\end{array}$ & $\begin{array}{l}\text { Apenas uma planta } \\
\text { situada no Brasil, } \\
\text { estudada neste } \\
\text { trabalho. }\end{array}$ & $\begin{array}{l}\text { Empresa brasileira } \\
\text { com uma única } \\
\text { planta, estudada } \\
\text { neste trabalho. }\end{array}$ \\
\hline $\begin{array}{l}\text { Funcionários } \\
\text { (valores } \\
\text { aproximados) }\end{array}$ & $\begin{array}{l}550 \\
\text { funcionários, mais } \\
\text { 350 funcionários } \\
\text { terceirizados }\end{array}$ & $\begin{array}{l}400 \\
\text { funcionários }\end{array}$ & $\begin{array}{l}300 \\
\text { funcionários }\end{array}$ & $\begin{array}{l}200 \\
\text { funcionários }\end{array}$ \\
\hline Clientes & $\begin{array}{l}\text { A montadora de } \\
\text { automóveis. }\end{array}$ & $\begin{array}{c}\text { Todas as } \\
\text { montadoras de } \\
\text { motores exceto uma, } \\
\text { para a qual fornece } \\
\text { peças de reposição. }\end{array}$ & $\begin{array}{c}\text { Tanto as } \\
\text { montadoras de } \\
\text { motores quanto } \\
\text { algumas empresas } \\
\text { de autopeças. }\end{array}$ & $\begin{array}{l}\text { A montadora } \\
\text { estudada é seu } \\
\text { principal cliente. }\end{array}$ \\
\hline $\begin{array}{l}\text { Principais } \\
\text { produtos } \\
\text { fabricados } \\
\text { nas plantas } \\
\text { estudadas }\end{array}$ & $\begin{array}{l}\text { Motores para } \\
\text { automóveis } \\
\text { (motores 1.o a 1.6, } \\
\text { envolvendo uma } \\
\text { grande diversidade } \\
\text { de produtos). } \\
\text { Tal diversidade } \\
\text { aumentou } \\
\text { consideravelmente } \\
\text { nos últimos anos. }\end{array}$ & $\begin{array}{l}\text { Embreagens para } \\
\text { veículos de passeio, } \\
\text { veículos pesados e } \\
\text { agrícolas e mercado } \\
\text { de reposição. }\end{array}$ & $\begin{array}{c}\text { No setor } \\
\text { automotivo, produz } \\
\text { molas para motores } \\
\text { e molas para } \\
\text { embreagens. }\end{array}$ & $\begin{array}{l}\text { Coletores de } \\
\text { escapamento } \\
\text { (produzidos com } \\
\text { ferro fundido } \\
\text { vermicular) }\end{array}$ \\
\hline $\begin{array}{l}\text { Autonomia } \\
\text { tecnológica }\end{array}$ & $\begin{array}{l}\text { Possui autonomia } \\
\text { para desenvolver } \\
\text { motores, a partir } \\
\text { de outros já } \\
\text { existentes. }\end{array}$ & $\begin{array}{l}\text { Autonomia } \\
\text { também para } \\
\text { inovações } \\
\text { em processos. }\end{array}$ & $\begin{array}{l}\text { A autonomia em } \\
\text { relação à matriz } \\
\text { estrangeira tem } \\
\text { aumentado } \\
\text { bastante, em } \\
\text { função do } \\
\text { aumento dos } \\
\text { desenvolvimentos } \\
\text { tecnológicos } \\
\text { realizados na } \\
\text { subsidiária } \\
\text { brasileira. }\end{array}$ & $\begin{array}{l}\text { Possui autonomia } \\
\text { para desenvolver } \\
\text { embreagens } \\
\text { a partir de outras } \\
\text { já existentes. }\end{array}$ \\
\hline $\begin{array}{l}\text { Autonomia } \\
\text { também para } \\
\text { inovações } \\
\text { em processos } \\
\text { de produção }\end{array}$ & $\begin{array}{l}\text { A autonomia em } \\
\text { relação à matriz } \\
\text { estrangeira tem } \\
\text { aumentado } \\
\text { bastante devido } \\
\text { ao aumento dos } \\
\text { desenvolvimen- } \\
\text { tos tecnológicos } \\
\text { realizados na } \\
\text { subsidiária } \\
\text { brasileira. }\end{array}$ & $\begin{array}{l}\text { Possui autonomia } \\
\text { para realizar } \\
\text { inovações } \\
\text { incrementais em } \\
\text { produtos, a partir } \\
\text { de especificações } \\
\text { de clientes. }\end{array}$ & $\begin{array}{c}\text { Autonomia } \\
\text { também para } \\
\text { desenvolver novos } \\
\text { materiais } \\
\text { e novos processos } \\
\text { de produção. }\end{array}$ & $\begin{array}{l}\text { Possui autonomia } \\
\text { para desenvolver } \\
\text { produtos, } \\
\text { em parceria } \\
\text { com a montadora, } \\
\text { além de inovações } \\
\text { em processos. }\end{array}$ \\
\hline
\end{tabular}

\section{QUADRO 2 - CARACTERÍSTICAS GERAIS DAS CADEIAS DAS EMPRESAS ESTUDADAS}


(continuação)

\begin{tabular}{|c|c|c|c|c|}
\hline & MONTADORA & FORNECEDOR “A” & FORNECEDOR "B" & FORNECEDOR “C” \\
\hline $\begin{array}{l}\text { Relações de } \\
\text { fornecimento } \\
\text { entre as } \\
\text { empresas } \\
\text { estudadas }\end{array}$ & $\begin{array}{c}\text { Os três } \\
\text { fornecedores } \\
\text { estudados } \\
\text { consideram a } \\
\text { montadora como } \\
\text { cliente importante, } \\
\text { sobretudo a } \\
\text { empresa "C". }\end{array}$ & $\begin{array}{l}\text { A empresa “A" } \\
\text { destina parcela } \\
\text { significativa } \\
\text { de seu volume } \\
\text { de produção } \\
\text { à montadora } \\
\text { estudada. }\end{array}$ & $\begin{array}{l}\text { Fornece tanto } \\
\text { para a montadora } \\
\text { estudada quanto } \\
\text { para o fornecedor } \\
\text { "A", sendo este } \\
\text { último seu } 4^{\circ} \\
\text { maior cliente em } \\
\text { vendas. }\end{array}$ & $\begin{array}{c}\text { Destina à } \\
\text { montadora } \\
\text { estudada } \\
\text { aproximadamente } \\
\text { 90\% de seu volume } \\
\text { total de produção. }\end{array}$ \\
\hline $\begin{array}{l}\text { Número de } \\
\text { fornecedores } \\
\text { (valores } \\
\text { aproximados) }\end{array}$ & $\begin{array}{c}130 \\
\text { O número } \\
\text { aumentou nos } \\
\text { últimos anos, com } \\
\text { o aumento da } \\
\text { diversidade } \\
\text { de produtos. }\end{array}$ & $\begin{array}{c}80 \\
\text { O número } \\
\text { aumentou nos } \\
\text { últimos anos, } \\
\text { com o aumento } \\
\text { do número de } \\
\text { fornecedores não- } \\
\text { ativos (reserva). }\end{array}$ & $\begin{array}{c}6 \\
\text { Do total de } 15 \\
\text { fornecedores, } 6 \\
\text { fornecem insumos } \\
\text { para produtos da } \\
\text { linha automotiva } \\
\text { da empresa. }\end{array}$ & - \\
\hline $\begin{array}{c}\text { Critérios } \\
\text { de seleção } \\
\text { e avaliação } \\
\text { de fornecedores }\end{array}$ & $\begin{array}{c}\text { Preço, capacitação } \\
\text { tecnológica } \\
\text { e qualidade. }\end{array}$ & Preço & Preço & Preço \\
\hline $\begin{array}{l}\text { Número de } \\
\text { fornecedores } \\
\text { por } \\
\text { componente } \\
\text { terceirizado }\end{array}$ & $\begin{array}{c}\text { O número varia } \\
\text { conforme o } \\
\text { componente. } \\
\text { Na maioria dos } \\
\text { casos, existem } \\
2 \text { fornecedores } \\
\text { por componente, } \\
\text { podendo haver } \\
\text { também casos de } 1 \\
\text { ou } 3 \text { fornecedores } \\
\text { por peça. }\end{array}$ & $\begin{array}{c}\text { Possui um } \\
\text { fornecedor por } \\
\text { item terceirizado, } \\
\text { porém para cada } \\
\text { item existem } \\
\text { fornecedores } \\
\text { desenvolvidos } \\
\text { como "reserva", } \\
\text { caso ocorram } \\
\text { problemas com } \\
\text { algum fornecedor } \\
\text { ativo. }\end{array}$ & $\begin{array}{c}\text { Possui } 3 \\
\text { fornecedores de } \\
\text { arames para molas, } \\
\text { seu principal } \\
\text { insumo. }\end{array}$ & $\begin{array}{c}\text { Possui } \\
\text { fornecedores de } \\
\text { areia de fundição, } \\
\text { gusa, ligas e } \\
\text { produtos químicos } \\
\text { em geral. }\end{array}$ \\
\hline Terceirização & $\begin{array}{l}\text { Desde o início da } \\
\text { produção da planta, } \\
\text { possui alto nível } \\
\text { de outsourcing, } \\
\text { realizando } \\
\text { internamente } \\
\text { apenas a usinagem } \\
\text { dos blocos dos } \\
\text { motores. Os demais } \\
\text { componentes, } \\
\text { incluindo a } \\
\text { fundição, são } \\
\text { terceirizados. }\end{array}$ & $\begin{array}{c}\text { Terceiriza } \\
\text { componentes } \\
\text { que não são } \\
\text { considerados } \\
\text { tecnologicamente } \\
\text { estratégicos para a } \\
\text { empresa. }\end{array}$ & $\begin{array}{l}\text { Adquire arames } \\
\text { para a produção } \\
\text { de molas. }\end{array}$ & $\begin{array}{c}\text { A usinagem era } \\
\text { completamente } \\
\text { terceirizada, mas } \\
\text { a empresa passou } \\
\text { a fazer cerca de } \\
\text { 70\% internamente. } \\
\text { A rebarbação das } \\
\text { peças é terceirizada. }\end{array}$ \\
\hline
\end{tabular}

\section{QUADRO 2 - CARACTERÍSTICAS GERAIS DAS CADEIAS DAS EMPRESAS ESTUDADAS}

(continua) 
(continuação)

\begin{tabular}{|c|c|c|c|c|}
\hline & MONTADORA & FORNECEDOR "A" & FORNECEDOR "B" & FORNECEDOR “C” \\
\hline $\begin{array}{l}\text { Conteúdo } \\
\text { tecnológico dos } \\
\text { componentes } \\
\text { para motores }\end{array}$ & $\begin{array}{c}\text { Existem } \\
\text { componentes } \\
\text { cuja tecnologia } \\
\text { é de domínio de } \\
\text { fornecedores (ex.: } \\
\text { componentes do } \\
\text { sistema de ignição, } \\
\text { válvulas injetoras, } \\
\text { embreagens, } \\
\text { etc.); outros, cujo } \\
\text { desenvolvimento } \\
\text { do produto envolve } \\
\text { tanto a montadora } \\
\text { quanto o fornecedor } \\
\text { (ex.: software } \\
\text { do sistema de } \\
\text { injeção eletrônica, } \\
\text { tecnologia } \\
\text { de motores } \\
\text { bicombustíveis); e } \\
\text { há ainda casos em } \\
\text { que a montadora } \\
\text { cede o design do } \\
\text { produto para o } \\
\text { fornecedor (ex.: } \\
\text { coletor de escape, } \\
\text { cárter, etc.). }\end{array}$ & $\begin{array}{l}\text { A empresa domina } \\
\text { a tecnologia dos } \\
\text { produtos fornecidos } \\
\text { à(s) montadora(s). } \\
\text { Tem autonomia } \\
\text { para desenvolver } \\
\text { novas embreagens } \\
\text { com base em } \\
\text { especificações } \\
\text { impostas pelas } \\
\text { montadoras de } \\
\text { motores quando } \\
\text { estas lançam } \\
\text { novos produtos. } \\
\text { Do mesmo modo, } \\
\text { passa especificações } \\
\text { para fornecedores } \\
\text { desenvolverem } \\
\text { novos produtos, } \\
\text { adaptados às novas } \\
\text { embreagens. }\end{array}$ & $\begin{array}{l}\text { A empresa domina } \\
\text { a tecnologia dos } \\
\text { produtos fornecidos } \\
\text { aos clientes, tendo } \\
\text { autonomia para } \\
\text { desenvolver novas } \\
\text { molas a partir de } \\
\text { especificações } \\
\text { impostas por } \\
\text { eles. Além disso, } \\
\text { desenvolve novos } \\
\text { materiais e novos } \\
\text { processos de } \\
\text { produção. Há casos } \\
\text { em que } \\
\text { a empresa } \\
\text { desenvolve } \\
\text { fornecedores, } \\
\text { quando necessita } \\
\text { de novos materiais. }\end{array}$ & $\begin{array}{l}\text { A montadora } \\
\text { desenvolveu a } \\
\text { empresa "C" } \\
\text { para lhe fornecer } \\
\text { produtos de acordo } \\
\text { com especificações } \\
\text { da matriz. Para } \\
\text { isso, investiu } \\
\text { em máquinas e } \\
\text { equipamentos, } \\
\text { normas de } \\
\text { qualidade e pessoal } \\
\text { qualificado para } \\
\text { trabalhar no } \\
\text { fornecedor, até que } \\
\text { este se tornasse } \\
\text { capacitado para } \\
\text { a produção. }\end{array}$ \\
\hline Contratos & $\begin{array}{l}\text { Contratos formais, } \\
\text { mas há também } \\
\text { pedidos informais } \\
\text { (devido à grande } \\
\text { flexibilidade de } \\
\text { mix e volume). }\end{array}$ & Contratos formais & $\begin{array}{l}\text { Os contratos são } \\
\text { específicos para } \\
\text { cada cliente, } \\
\text { com períodos } \\
\text { de duração } \\
\text { diferenciados. }\end{array}$ & $\begin{array}{l}\text { Contratos } \\
\text { formais e pedidos } \\
\text { informais. }\end{array}$ \\
\hline
\end{tabular}

\section{QUADRO 2 - CARACTERÍSTICAS GERAIS DAS CADEIAS DAS EMPRESAS ESTUDADAS}

\section{Análise dos estudos de caso}

O Quadro 2 sintetiza as principais informações relativas às empresas, permitindo a comparação entre as mesmas em diversos aspectos estudados. Já o Quadro 3 apresenta características relevantes das relações entre tais empresas, que fundamentam a análise dos casos, com base em conceitos ligados à Economia de Custos de Transação. 


\begin{tabular}{|c|c|c|c|c|}
\hline & $\begin{array}{c}\text { RELAÇÕES DA } \\
\text { MONTADORA COM } \\
\text { A EMPRESA “A" }\end{array}$ & $\begin{array}{l}\text { RELAÇÕES DA } \\
\text { MONTADORA COM } \\
\text { A EMPRESA “B” }\end{array}$ & $\begin{array}{l}\text { RELAÇÕES DA } \\
\text { MONTADORA COM } \\
\text { A EMPRESA "C" }\end{array}$ & $\begin{array}{c}\text { RELAÇÕES ENTRE } \\
\text { AS EMPRESAS “A” } \\
\text { E "B" }\end{array}$ \\
\hline $\begin{array}{l}\text { Especificidade } \\
\text { de ativos }\end{array}$ & $\begin{array}{c}\text { Moderada } \\
\text { especificidade de } \\
\text { ativos. } \\
\text { A montadora, } \\
\text { quando desenvolve } \\
\text { um novo motor, } \\
\text { passa especificações } \\
\text { para a empresa } \\
\text { "A" desenvolver } \\
\text { embreagens } \\
\text { adaptadas ao novo } \\
\text { motor. A empresa } \\
\text { "A", na fase de } \\
\text { desenvolvimento, } \\
\text { testa seu novo } \\
\text { produto junto à } \\
\text { montadora e, caso } \\
\text { haja algum problema, } \\
\text { podem inclusive } \\
\text { resolver juntas. } \\
\text { Nessa fase, a troca } \\
\text { de informações entre } \\
\text { ambas é grande. }\end{array}$ & $\begin{array}{c}\text { A montadora, } \\
\text { quando desenvolve } \\
\text { um novo motor, } \\
\text { passa especificações } \\
\text { para a empresa "B" } \\
\text { desenvolver molas } \\
\text { adaptadas ao novo } \\
\text { motor. A empresa } \\
\text { "B”, na fase de } \\
\text { desenvolvimento, } \\
\text { testa seu novo produto } \\
\text { junto à montadora } \\
\text { e, caso haja algum } \\
\text { problema, podem } \\
\text { inclusive resolver } \\
\text { juntas. } \\
\text { Nessa fase, a troca } \\
\text { de informações entre } \\
\text { ambas é grande. } \\
\text { Se a empresa "B” } \\
\text { necessitar de uso } \\
\text { de novos materiais } \\
\text { para o novo } \\
\text { produto, em alguns } \\
\text { casos desenvolve } \\
\text { fornecedores para } \\
\text { obter tais insumos. }\end{array}$ & $\begin{array}{c}\text { Alta especificidade } \\
\text { de ativos. } \\
\text { A montadora } \\
\text { investiu em ativos } \\
\text { físicos (máquinas, } \\
\text { equipamentos e } \\
\text { ferramental) e } \\
\text { humanos (tecnologia, } \\
\text { informações } \\
\text { e engenheiros } \\
\text { da montadora } \\
\text { trabalhando na planta } \\
\text { do fornecedor). } \\
\text { A empresa "C" } \\
\text { desenvolve processos } \\
\text { de produção para a } \\
\text { fabricação do produto. }\end{array}$ & $\begin{array}{c}\text { Moderada } \\
\text { especificidade de } \\
\text { ativos. A empresa } \\
\text { "A", quando } \\
\text { desenvolve uma } \\
\text { nova embreagem, } \\
\text { passa especificações } \\
\text { para a empresa "B" } \\
\text { desenvolver molas } \\
\text { apropriadas. A } \\
\text { empresa "B”, na fase } \\
\text { de desenvolvimento, } \\
\text { testa seu novo } \\
\text { produto junto à } \\
\text { empresa "A" e, } \\
\text { caso haja algum } \\
\text { problema, podem } \\
\text { inclusive resolver } \\
\text { juntas. } \\
\text { Nessa fase, a troca } \\
\text { de informações entre } \\
\text { ambas é grande. } \\
\text { Se a empresa "B" } \\
\text { necessitar de uso } \\
\text { de novos materiais } \\
\text { para o novo } \\
\text { produto, em alguns } \\
\text { casos desenvolve } \\
\text { fornecedores para } \\
\text { obter tais insumos. }\end{array}$ \\
\hline $\begin{array}{c}\text { Relações } \\
\text { de poder entre } \\
\text { as empresas }\end{array}$ & $\begin{array}{l}\text { A empresa "A" domina } \\
\text { a tecnologia dos } \\
\text { produtos entregues à } \\
\text { montadora. } \\
\text { Fornece à montadora } \\
\text { estudada parcela } \\
\text { significativa do seu } \\
\text { volume de produção, } \\
\text { fornecendo também a } \\
\text { outras montadoras. } \\
\text { O mercado no qual "A" } \\
\text { está inserida apresenta } \\
\text { estrutura duopolizada } \\
\text { no Brasil, sendo que } \\
\text { apenas uma empresa } \\
\text { concorrente possui } \\
\text { capacidade para suprir } \\
\text { os mesmos produtos. }\end{array}$ & $\begin{array}{c}\text { A empresa "B" domina a } \\
\text { tecnologia dos produtos } \\
\text { entregues aos clientes. } \\
\text { A empresa "B" fornece } \\
\text { para a montadora } \\
\text { estudada uma parcela } \\
\text { pequena de seu volume } \\
\text { de produção. }\end{array}$ & $\begin{array}{c}\text { Por ter investido na } \\
\text { empresa "C" e por ceder } \\
\text { o design do produto, a } \\
\text { montadora possui alto } \\
\text { poder de barganha em } \\
\text { relação ao fornecedor. } \\
\text { A montadora não possui } \\
\text { outro fornecedor de } \\
\text { coletor de escapamento } \\
\text { dentro das especificações } \\
\text { estabelecidas pela } \\
\text { matriz, a não ser a } \\
\text { empresa "C". }\end{array}$ & $\begin{array}{c}\text { As empresas "A" e "B" } \\
\text { dominam a tecnologia } \\
\text { dos produtos } \\
\text { entregues aos clientes. } \\
\text { Os principais clientes } \\
\text { da empresa "B" } \\
\text { são empresas de } \\
\text { autopeças, nas quais } \\
\text { a empresa "A" ocupa } \\
\text { posição de } 4^{\circ} \text { maior } \\
\text { cliente em volume de } \\
\text { produção. }\end{array}$ \\
\hline
\end{tabular}

\section{QUADRO 3 - ASPECTOS RELEVANTES DAS RELAÇÕES ENTRE AS EMPRESAS ESTUDADAS}


(continuação)

\begin{tabular}{|c|c|c|c|c|}
\hline & $\begin{array}{l}\text { RELAÇÕES DA } \\
\text { MONTADORA COM A } \\
\text { EMPRESA “A” }\end{array}$ & $\begin{array}{c}\text { RELAÇÕES DA } \\
\text { MONTADORA COM A } \\
\text { EMPRESA “A” }\end{array}$ & $\begin{array}{l}\text { RELAÇÕES DA } \\
\text { MONTADORA COM A } \\
\text { EMPRESA “A” }\end{array}$ & $\begin{array}{l}\text { RELAÇÕES ENTRE } \\
\text { AS EMPRESAS “A” } \\
\text { E "B” }\end{array}$ \\
\hline $\begin{array}{l}\text { Freqüência } \\
\text { das relações }\end{array}$ & $\begin{array}{l}\text { A montadora mantém } \\
\text { relações com a empresa } \\
\text { "A" desde quando esta } \\
\text { iniciou a produção } \\
\text { de sua fábrica (1997), } \\
\text { um ano após o início } \\
\text { da produção da fábrica } \\
\text { da montadora. } \\
\text { A montadora entrega } \\
\text { motores diariamente } \\
\text { para a montadora } \\
\text { de automóveis. } \\
\text { Faz pedidos para os } \\
\text { fornecedores a cada } \\
\text { 15 dias, e recebe } \\
\text { os componentes } \\
\text { diariamente. }\end{array}$ & $\begin{array}{c}\text { Desde quando a } \\
\text { empresa “B” iniciou a } \\
\text { produção de sua fábrica } \\
\text { (1999), mantém relações } \\
\text { com a montadora. } \\
\text { As entregas para a } \\
\text { montadora são feitas } \\
\text { diariamente. }\end{array}$ & $\begin{array}{l}\text { A empresa “C", em 1996, } \\
\text { modificou sua linha } \\
\text { de produtos para atender } \\
\text { à montadora, assim } \\
\text { que esta montadora } \\
\text { inaugurou a fábrica. } \\
\text { As entregas para a } \\
\text { montadora são feitas } \\
\text { diariamente. }\end{array}$ & $\begin{array}{l}\text { Desde quando a } \\
\text { empresa "B” iniciou } \\
\text { a produção de sua } \\
\text { fábrica (1999), } \\
\text { mantém relações } \\
\text { com a empresa “A". } \\
\text { As entregas são feitas } \\
\text { diariamente. }\end{array}$ \\
\hline
\end{tabular}

\section{QUADRO 3 - ASPECTOS RELEVANTES DASRELAÇÕES} ENTRE AS EMPRESAS ESTUDADAS

Antes de proceder à analise dos estudos de caso, é adequado frisar que neste trabalho se deseja explorar como os conceitos da ECT podem ajudar a explicar o padrão verificado nessas relações, bem como sugerir possíveis justificativas para a escolha desses padrões.

Inicialmente, as empresas escolhidas para esse caso pertencem ao setor automotivo, de produção de motores para automóveis. Considerando o número de empregados, os fornecedores podem ser considerados de médio porte e, embora a planta de produção de motores conte com número similar de funcionários, pertence a uma montadora de veículos multinacional e de grande porte.

Sob uma ótica geral, tanto a montadora quanto o fornecedor "A" utilizam apenas um fornecedor por componente, embora tenham outros fornecedores desenvolvidos. Dessa forma, ambas as empresas podem se valer de relacionamentos mais estreitos com menor número de fornecedores para aumentar o grau de cooperação com seus fornecedores e auferir os benefícios competitivos como compartilhamento de informações (Fruin 1992 \& Clark \& Fujimoto 1991 \& Nishigushi 1994) e facilidade de investimentos (Dyer 1996).

Contudo, os fornecedores desenvolvidos mas não em fornecimento ativo servem como salvaguarda para ações oportunistas das empresas atuais. Caso haja problemas de fornecimento, a montadora e a empresa " $\mathrm{A}$ " podem transferir o fornecimento para as empresas desenvolvidas. Além disso, o fato de existirem empresas em condições de assumir o fornecimento confere poder de barganha à montadora e à empresa "A", que pode se utilizar dessa situação para inibir o comportamento oportunista dos fornecedores quando estes exigirem aumento de preços ou alterarem as condições de fornecimento acordadas. 
Flexibilidade, aspecto muito enfatizado pelos entrevistados, tem impacto na estrutura da cadeia de suprimentos e nos relacionamentos entre as empresas que as compõem. Assim, uma estratégia que parece ser adotada pela companhia estudada é desenvolver relacionamentos estreitos com fornecedores e repassar a necessidade de flexibilidade para os mesmos. Dessa forma, a montadora atribui a seus fornecedores imediatos a responsabilidade por aumentar flexibilidade e repassar essa demanda ao longo das camadas inferiores da cadeia (Maia \& Cerra 2004).

Todas as empresas dos casos estudados optam por utilizarem contratos formais para regerem as suas transações de fornecimento, mesmo que os pedidos possam ser efetuados de maneira informal. Dessa forma, em consonância com Barney (1999) e Mcnally (2002), as empresas optam por uma estrutura de governança híbrida, por meio de subcontratação formal, buscando combinar aspectos positivos outras duas formas de governança: mercado e integração vertical. Diferentemente do Mercado Spot, as empresas não podem recorrer a qualquer agente do mercado para obter seus produtos ou serviços, contudo, não há a propriedade dos compradores sobre esses fornecedores, conforme ocorre na Integração Vertical.

As empresas buscam, dessa forma, alinhar transações, que diferem em seus atributos, com estruturas de governança, que por sua vez diferem em seus custos e competências (Williamson 1994).

Nesse contexto, embora o prazo dos contratos possa variar, as relações entre as empresas tendem a ser de longo prazo. Conforme destaca Helper (1987) apud Swaminathan et al. (2002), relações de longo prazo com fornecedores podem ter desempenhos superiores aos de curto prazo quando: (1) produtos são complexos, (2) tecnologia sofre constantes alterações, (3) existe uma interação complicada entre os componentes, ou (4) quando o relacionamento comercial requer habilidades humanas especializadas.

Os casos aqui apresentados parecem corroborar diretamente as três primeiras condições citadas acima. No que se refere à complexidade dos produtos e à interação entre os componentes, observou-se que quando a montadora de motores desenvolve um novo produto, os fornecedores imediatos (diretos) recebem as especificações necessárias para desenvolver componentes que se adaptem ao novo motor; do mesmo modo, os fornecedores imediatos passam para alguns de seus fornecedores (os fornecedores de segundo nível das montadoras) especificações para a produção de componentes voltados para os novos componentes.

Uma outra possibilidade é a de desenvolvimento de produtos em conjunto (codesign), no qual o design do produto envolve investimentos em capacitação tecnológica de ambas as partes envolvidas na relação. Embora a montadora não realize co-design com esses fornecedores estudados, através das entrevistas pôdese verificar que ela o faz com cerca de $30 \%$ dos fornecedores da cadeia, como no caso do fornecedor do software do sistema de injeção eletrônica, dos motores bicombustíveis e dos turbocompressores, por exemplo. 
Durante a fase de desenvolvimento de novos produtos, a troca de informações das empresas "A" e "B" com a montadora é grande, havendo situações nas quais a empresa " $\mathrm{B}$ " necessita desenvolver novos materiais para atingir as especificações de clientes em um novo produto.

O terceiro aspecto de Helper (1987) apud Swaminathan et al. (2002) se refere à tecnologia. Em cerca de 45\% dos fornecedores, incluindo "A" e "B", embora a tecnologia do componente esteja sob domínio do fornecedor, o trabalho de "aplicação" do mesmo é coordenado pela Engenharia da montadora, a qual também define as normas de aprovação de cada componente. Exemplos de componentes nesse caso são as embreagens, molas para válvulas de motores, os componentes eletrônicos, entre outros.

As relações observadas nesse conjunto de empresas caracterizam-se por relações de fornecimento nas quais cada empresa domina a tecnologia necessária para a produção de seus componentes. Entretanto, existem casos em que o fornecedor, tendo capacidade tecnológica limitada, recebe das montadoras o design do produto, restando ao fornecedor adaptar tal projeto ao seu processo de produção. Nesse conjunto de fornecedores, em que se enquadram cerca de $25 \%$ das empresas, incluindo o fornecedor "C", as atividades de Desenvolvimento de Produtos restringem-se a inovações em processos de produção. Exemplos de componentes nesse caso são: cárter, agregados de motor (como, por exemplo, tampa do motor), coletor de escapamento, etc.

De forma a buscar compreender os efeitos da especificidade dos ativos nas transações analisadas, criou-se uma escala subjetiva, com base na comparação da percepção dos níveis de especificidade nos diferentes casos analisados.

A possibilidade de comportamentos oportunistas nas relações montadoraempresa "A" e montadora-empresa "B" é considerada baixa. Conforme destacam Farina et al. (1999), a reputação em torno de uma marca tem impactos nos custos de transação. Tanto a montadora quanto as empresas "A" e "B" são organizações de renome e, sobretudo, com reputação mútua construída durante anos. Embora no Brasil as relações entre a montadora e esses fornecedores sejam relativamente recentes, em seus países de origem tais relacionamentos ocorrem há mais tempo.

Deve-se também considerar que a montadora possui certo conhecimento dos processos e formas de produção dos componentes providos por esses fornecedores, embora não detenha a tecnologia necessária para produzi-los. Dessa forma, reduz-se ligeiramente a complexidade envolvida na medida em que se diminui ao menos a assimetria informacional a respeito das tecnologias envolvidas e do processo produtivo.

No caso dos ativos envolvidos principalmente na relação entre a montadora e a empresa "A", ocorre a especificidade de ativos físicos apresentada por Williamson (1979), na medida em que parcela significativa da produção de "A" é 
destinada à montadora e uma conduta dolosa faria com que a empresa perdesse a venda de aproximadamente 140.000 produtos, considerando os dados da Anfavea (2006) para a produção da montadora (sem considerar o mercado de reposição). Por outro lado, uma conduta inadequada por parte da montadora obrigaria a mesma a comprar componentes da outra única empresa disponível (mercado duopolizado), fato que tornaria a montadora ainda mais vulnerável a atitudes oportunistas. Além disso, a ocorrência de transações praticamente diárias resulta na criação de boa reputação entre os entes participantes.

No caso da montadora e da empresa "B", os componentes transacionados correspondem a uma pequena parcela para ambas as partes envolvidas. Nesse caso, a especificidade de ativos pode ser considerada menor, sendo principalmente influenciada pelo baixo conteúdo tecnológico das peças fornecidas. Caso ocorresse ação dolosa nessa relação, a montadora pode conseguir fornecimento de seus produtos a partir de outras empresas e, embora pudesse perder significativa fonte de receita, a empresa " $\mathrm{B}$ ” poderia passar a produzir outros produtos para atender a clientes diferentes.

A recorrência das relações ocorre nos quatro relacionamentos estudados, com as entregas sendo feitas diariamente e os pedidos tendo periodicidade variável. Conforme destacado por Lorenzoni \& Lipparini (1999), repetidas transações entre firmas, com o decorrer do tempo, levam a custos de transação mais baixos, o que permite que os atores econômicos ganhem vantagem subcontratando fornecedores que desenvolvem suas próprias competências.

Ao observar as relações da montadora com a empresa "C", temos um caso no qual a especificidade física de ativos pode ser considerada extremamente alta, dado que a montadora praticamente desenvolveu o fornecedor para que pudesse produzir componentes de acordo com suas especificações. A montadora, além de ceder o design do produto, investiu em máquinas, equipamentos e ferramental de produção e engenheiros da montadora trabalharam na planta do fornecedor, quando conhecimentos e técnicas de produção foram passados em um período de grandes trocas de informação.

Após essa fase inicial, o fornecedor tem feito investimentos no sentido de cumprir as exigências da montadora quanto a qualidade dos produtos, técnicas utilizadas, prazos de entrega, etc.

Contudo, embora a especificidade de ativos possa ser alta, a possibilidade de comportamento oportunista também pode ser considerada baixa, dado que a própria montadora ajudou a desenvolver o fornecedor, e logo detém conhecimento a respeito de todo o processo.

Dessa forma, similarmente ao caso entre montadora e as outras empresas, reduz-se ligeiramente a complexidade envolvida na medida em que se diminui ao menos a assimetria informacional a respeito das tecnologias envolvidas e do processo produtivo. 
O volume transacionado também age como fator redutor da possibilidade oportunista nessa relação. Praticamente $90 \%$ da produção de "C" é destinada à montadora de motores analisada, e uma ação de má-fé certamente acarretaria a falência da fábrica. Em contrapartida, a montadora também não possui interesse em atitudes oportunistas, pois não conseguiria obter maior retorno sobre o investimento inicial feito para o desenvolvimento de "C", e não conseguiria auferir reduções de custo trazidas pelo poder de barganha que possui frente a "C", poder que permite à montadora estabelecer reduções progressivas no preço pago pelos componentes.

Vale ressaltar que cerca de $30 \%$ dos fornecedores dessa montadora, incluindo as empresas "A", "B" e "C", localizam-se a uma distância de até 150 quilômetros, o que sugere a presença de especificidade locacional. A proximidade física entre a montadora e essas empresas contribui para a diminuição de custos de transporte e inventários, a rapidez das entregas e a maior facilidade para resolução de problemas. Considerando o restante dos fornecedores, cerca de 60\% deles localiza-se a uma distância entre 150 e 300 quilômetros da montadora e os demais a uma distância acima de 300 quilômetros.

Considerando a relação entre possibilidade de ação oportunista e a especificidade dos ativos envolvidos, os estudos aqui parecem corroborar as pesquisas de Dyer (1997), Folta (1998) e Combs \& Ketchen Jr (1999). Embora a especificidade de ativos tenda a aumentar os custos de transação por meio do aumento da possibilidade de comportamento oportunista, essa relação é mediada por fatores como complexidade e freqüência/volume de transações. Reportando-se ao caso da montadora com a empresa "C", embora ocorra alta especificidade de ativos, a assimetria informacional envolvida é reduzida, dado que a montadora desenvolveu o fornecedor, além de existirem fatores externos como a maximização dos retornos sobre os investimentos feitos pela montadora.

\section{Conclusões e considerações finais}

O trabalho aqui apresentado procurou discutir o relacionamento entre uma montadora de motores para automóveis e três empresas fornecedoras, a partir do ferramental de análise provido pela Economia de Custos de Transação. Desse modo, foram considerados os diversos elementos condicionantes dos custos de transação, como a racionalidade limitada, o comportamento oportunista, a especificidade de ativos, a incerteza e a freqüência das relações. De acordo com a importância de cada elemento, um mecanismo é escolhido entre as formas de coordenar uma transação - mercado spot, hierarquia ou formas híbridas.

A Economia de Custos de Transação tem se mostrado uma teoria importante para pesquisa em cadeias de suprimentos, podendo ser utilizada para: avaliar a qualidade e riqueza das relações entre empresas compradoras e vendedoras; considerar as implicações das escolhas organizacionais em desenvolver uma 
transação ou atividade internamente à empresa, no mercado ou através de formas híbridas; e auxiliar a avaliar como vários tipos de investimentos com outras firmas podem contribuir para a formação de capacidades de longo prazo.

A montadora estudada instalou sua unidade produtiva no Brasil modernizando seus produtos e processos de fabricação e implementando uma variante do modelo japonês de organização da produção e do trabalho, denominado lean production (produção enxuta) por Womack et al. (1992).

Assim como ocorreu com outras montadoras, essa montadora passou por amplo processo de desverticalização de sua produção. A produção de uma parte significativa de componentes para motores foi terceirizada e apenas itens considerados tecnologicamente estratégicos continuaram sendo produzidos internamente.

A questão da desverticalização afeta diretamente, nos casos estudados e possivelmente nas relações dentro desse setor industrial, a assimetria informacional existente entre as distintas partes da transação. Como as montadoras detinham certo conhecimento do processo de produção das peças terceirizadas antes da oportunidade de realização do outsourcing, elas podem se valer desse conhecimento para reduzir a complexidade envolvida e assim inibir, ao menos parcialmente, comportamentos oportunistas das empresas que passaram a produzir as peças terceirizadas.

Além disso, as montadoras buscam utilizar uma forma de relação híbrida com seus fornecedores, que em momentos se aproxima da concorrência e em momentos se aproxima da cooperação. Semelhanças com a cooperação podem ser verificadas no fato de que tanto a montadora quanto o fornecedor "A" utilizam apenas um fornecedor por componente para aumentar o grau de cooperação com seus fornecedores, o que facilita o compartilhamento de informações (Fruin 1992 \& Clark \& Fujimoto 1991 \& Nishigushi 1994) e os investimentos (Dyer 1996).

Contudo, montadora e empresa "A" buscam fomentar certa "competição latente”, por meio de fornecedores desenvolvidos mas não em fornecimento. Caso haja problemas de fornecimento, a montadora e a empresa "A" podem transferir o fornecimento para as empresas desenvolvidas, aumentando seu poder de barganha e reduzindo ameaças do oportunismo.

A questão do poder de barganha é mencionada por Perrow (1986), com destaque para a maior alavancagem das maiores firmas. Se a maior firma é a compradora, o poder de compra permite a ela que encontre outra fonte de suprimento, e provavelmente faça isso mais rapidamente que o fornecedor desenvolva outro consumidor.

Outra constatação dos casos estudados, fortemente impactada pelo processo de desverticalização das montadoras, é que todas as empresas utilizam contratos formais para regerem as suas transações de fornecimento. Esse 
fato está fortemente relacionado à escolha da forma de relação híbrida da montadora com seus fornecedores, dado que a cooperação pode conferir os benefícios de proximidade, troca de conhecimentos e dependência presentes na integração vertical, enquanto a "competência latente" pode trazer os benefícios de competição por preços e condições de fornecimento presentes no mercado spot.

Nos casos foram verificados ao menos três questões diretamente relacionadas às proposições de Helper (1987) apud Swaminathan (2002), acerca da vantagem competitiva de relacionamentos cooperativos: (1) produtos são complexos, (2) tecnologia sofre constantes alterações e (3) existe uma interação complicada entre os componentes. Embora em casos como as relações entre montadora e empresa "B", e empresa "A" e empresa "B", os tópicos (1) e (2) sejam apenas parcialmente verificados, a questão da interação complexa entre os componentes constituintes dos motores gera cenário propício ao desenvolvimento da cooperação.

Considerando a relação entre possibilidade de ação oportunista e a especificidade dos ativos envolvidos, os estudos aqui parecem corroborar as pesquisas de Dyer (1997), Folta (1998) e Combs \& Ketchen Jr (1999). Embora a especificidade de ativos tenda a aumentar os custos de transação por meio do aumento da possibilidade de comportamento oportunista, essa relação é mediada por fatores como complexidade e freqüência de transações.

Em consonância com a teoria de ECT, estudos anteriores (Maia \& Cerra, 2005) indicavam que aspectos como a especificidade de ativos envolvida nas transações, a freqüência, o grau de incerteza e o comportamento oportunista podem alterar as relações de poder entre compradores e fornecedores.

Os estudos de caso aqui realizados acrescentam outros aspectos mediadores na relação "especificidade de ativos-comportamento oportunista". Principalmente emanados da relação montadora e empresa "C", caso no qual a especificidade de ativos foi considerada alta, fatores como a parcela da produção que é destinada à montadora (e por outro lado, o quanto essa parcela é relevante para o montante que a montadora adquire do componente), bem como o objetivo de maximização de retorno sobre investimentos (especificidade física de ativos) feitos no passado também devem ser avaliados nessas situações.

Embora a base de observação empírica possa ser considerada limitada para fazer recomendações sobre cadeias de suprimentos, é importante enfatizar que o estudo de caso realizado na montadora de automóveis incluiu questões que envolviam tanto os clientes quanto os fornecedores, de forma a cobrir a cadeia.

É necessário considerar, também, que os fornecedores da companhia estudada não são exclusivos, participando de várias cadeias do setor automotivo. Assim, os fornecedores principais servem, na maioria dos casos, montadoras diferentes e necessitam adotar estratégias compatíveis com seus clientes. 
Dado que devam ser distintas as influências que cada montadora exerce sobre os fornecedores, fica a proposta de um futuro trabalho para comparar os padrões de relacionamento no caso de determinados fornecedores que simultaneamente servem montadoras distintas, de forma a elucidar em que aspectos particulares a relação é afetada pelas diferentes estratégias empreendidas por tais montadoras.

A questão da cooperação foi aqui tratada sobre um prisma econômico, buscando retratar as vantagens em eficiência de relacionamentos desse tipo. Pesquisas adicionais podem ser realizadas no sentido de dar tratamento de cunho sociológico a essas relações, buscando identificar questões culturais, institucionais, etc. que sejam profícuas ao surgimento de confiança e cooperação.

A especificidade de ativos, embora mediada por outras questões aqui citadas, também pode ser objeto de pesquisas futuras no sentido de compreender mais aprofundadamente os fatores que a condicionam. Os investimentos realizados no passado, as características do processo que tornam os ativos específicos, entre outros, podem ser estudados de forma mais detalhada.

\section{Referências}

ALVES FILHO, A. \& RACHID, A. \& DONADONE, J. \& MARTINS, M. \& TRUZZI, O. \& BENTO, P. \& VANALLE, R. (2001). O consórcio modular e seus impactos na cadeia de suprimentos da fábrica de motores VW-São Carlos. Relatório Final, Projeto Temático, Processo FAPESP 97/13071-9.

ALVES FILHO,A.\& RACHID,A. \& NOGUEIRA, E. \& BENTO, P.\& VANALLE, R. \& MAIA, J. \& CERRA, A. (2006). Estratégias de Produção das Unidades Produtoras de Motores para Automóveis. Relatório Final, Projeto Temático, Processo CNPq 477515/03-7.

ALVES FILHO, A. \& CERRA, A. \& MAIA, J. \& SACOMANO NETO, M. \& BONADIO, P. (2004). "Pressupostos da Gestão da Cadeia de Suprimentos: evidências de estudos sobre a indústria automobilística." Gestão \& Produção 11(3): 275-88.

ANFAVEA (2006). "Anuário Estatístico da Indústria Automobilística Brasileira 2006." Associação Nacional dos Fabricantes de Veículos Automotores. URL [on line]: http:// www.anfavea.com.br.

AZEVEDO, P. F. (1996). Integração Vertical e Barganha. Tese de Doutorado, Departamento de Economia FEA/USP, São Paulo.

. \& ROCHA, M. M. (2003). "Governance Structure under Uncertainty: an empirical analysis of the petrochemical industry." Proceedings of 7th Annual Conference of the International Society for New Institutional Economics, Budapest.

BARNEY, J. B. (1999). "How a firm's capabilities affect boundary decisions." Sloan Management Review Spring: 137-45.

CLARK, K. \& FUJIMOTO, T. (1991). Product Development Performance. Boston: Harvard Business School Press. 
COMBS, J. \& KETCHEN JR, D. (1999). “Explaining interfirm cooperation and performance: toward a reconciliation of predictions from the resource-based view and organizational economics." Strategic Management Journal 20: 867-88.

DYER, J. H. (1996). "Specialized supplier networks as a source of competitive advantage: evidence from the auto industry." Strategic Management Journal 17: 271-91.

. (1997). "Effective interfirm collaboration: how firms maximize transaction costs and maximize transaction value." Strategic Management Journal 18: 535-56.

.\& CHU, W. (2000). "The determinants of trust in supplier-automaker relationships in the U.S., Japan and Korea." Journal of International Business Studies 31(2): 25985 .

.\& OUCHI, W. (1993). “Japanese-style partnership: giving companies a competitive edge." Sloan Management Review 14: 51-63.

FARINA, E. \& AZEVEDO, P. \& SAES, M. (1999). Competitividade: mercado, estado e organizações. São Paulo: Singular.

FIANI, R. (2002). “Teoria dos custos de Transação.” In: KUPFER, D. \& HASENCLEVER, L. Economia Industrial: Fundamentos Teóricos e Práticas no Brasil. 2. ed. Rio de Janeiro: Campus.

FOLTA, T. B. (1998). "Governance and uncertainty: the trade-off between administrative control and commitment." Strategic Management Journal 19: 1007-28.

FRUIN, M. (1992). The Japanese Enterprise System: Competitive Strategies and Cooperative Structures. Oxford: Oxford University.

GIL, A. C. (1999). Métodos e Técnicas de Pesquisa Social. 5. ed. São Paulo: Atlas.

GROVER, V. \& MALHOTRA, M. (2003). “Transaction cost framework in operations and supply chain management research: theory and measurement." Journal of Operations management 21: 457-73.

KOTABE, M. \& MARTIN, X. \& DOMOTO, H. (2003). "Gaining from vertical partnerships: knowledge transfer, relationship duration, and supplier performance improvement in the U.S. and Japanese automotive industries." Strategic Management Journal 24: 293 316.

LEIBLEIN, M. \& MILLER, D. (2003). "An empirical examination of transaction- and firm-level influences on the vertical boundaries of the firm." Strategic Management Journal 24: 839-59.

LIKER, J. \& WU, Y. (2000). "Japanese automakers, U.S. suppliers and supply chain superiority.” Sloan Management Review 21:81-93.

LORENZONI, G. \& LIPPARINI, A. (1999). "The leveraging of interfirm relationships as a distinctive organizational capability: a longitudinal study." Strategic Management Journal 20: 317-38.

MAIA, J. \& CERRA, A. (2005). "Using transaction cost economics as a tool to analyse Brazilian automotive supply chains." Proceedings of the International Symposium on Logistics, 3-5 July, Lisbon.

MAIA, J. \& CERRA, A. (2004). "Estratégia de Produção e Estratégia Tecnológica em uma montadora de motores para automóveis.” Anais. SEGET - Simpósio de Excelência em Gestão. 
MAIA, J. \& CERRA, A. \& ALVES FILHO, A. (2005). "Inter-relações entre Estratégia de Operações e Gestão da Cadeia de Suprimentos: Estudos de Caso no segmento de motores para automóveis." Gestão \& Produção 12(3): 377-91.

MCMILLAN, J. (1990). "Managing suppliers: incentive systems in Japanese and U.S. industry." California Management Review Summer: 38-54.

MCNALLY, R. C. (2002). Efficiency motives and institutional considerations in make-orbuy decisions. Thesis. Doctor of Philosophy in Business Administration, University of Illinois - Urbana-Champaign.

NISHIGUCHI, T. (1994). Strategic Industrial Sourcing: the Japanese advantage. New York: Oxford University Press.

PERROW, C. (1986). "Economic Theories of Organization." Theory and Society 15: 11-45.

SWAMINATHAN, A. \& HOETKER, G. \& MITCHELL, W. (2002). “(In)significant others: the impact of buyer-supplier relationships on the survival of modular and architectural component suppliers.” 2002.

TRIENEKENS, J. (1999). Management of process in chains: a research framework. Tese de Doutorado: Wageningen University.

WILLIAMSON, O. E. (1981). "The economics of organization: the transaction cost approach." American Journal of Sociology 87(3): 548-77.

WILLIAMSON, O. E. (1985). The economic institutions of capitalism. New York: The Free Press-McMillan.

WILLIAMSON, O. E. (1991). "Comparative economic organization: the analysis of discrete structural alternatives." Administrative Science Quarterly 36: 269-96.

WILLIAMSON, O. E. (1994). "Strategizing, Economizing, and Economic Organization." In: RUMELT, R. \& SCHENDEL, D. \& TEECE, D. Fundamental Issues in Strategy - a research agenda. Harvard: Harvard Business School Press. p.361-401.

WILLIAMSON, O. E. (1999). "Strategy research: governance and competence perspectives." Strategic Management Journal 20:1087-108.

WOMACK, J. \& JONES, D. \& ROOS, D. (1992). A máquina que mudou o mundo. Rio de Janeiro: Campus.

YIN, R. K. (1989). Case study research: design and methods. Newbury Park: Sage.

ZAHEER, A. \& MCEVILY, B. \& PERRONE, V. (1992). "Does Trust Matter? Exploring the Effects of Interorganizational and Interpersonal Trust on Performance." Organization Science 9: 141-59.

Submissão: 8 de novembro de 2006

Primeira resposta: 11 de fevereiro de 2007

Aceite: 19 de fevereiro de 2007 